\title{
ADMINISTRAÇÃO PÚBLICA E GESTÃO PARTICIPATIVA DE PROGRAMAS DE POLÍTICAS PÚBLICAS. JURIDICIDADE E ESTRATÉGIAS DE GESTÃO: UMA EXPERIÊNCIA NO PROGRAMA EDPOPSUS
}

\section{PUBLIC ADMINISTRATION AND PARTICIPATORY MANAGEMENT OF PUBLIC POLICY PROGRAMS. JURIDICITY AND MANAGEMENT STRATEGIES: AN EXPERIENCE IN THE EDPOPSUS PROGRAM}

\author{
Eugénio Antunes ${ }^{1}$ \\ Stênio de Freitas Barretto²
}

\begin{abstract}
Resumo
Este artigo analisa os aspectos jurídicos, sociais, econômicos e administrativos na estratégia da Administração Pública federal na adoção da Gestão Participativa como método de gestão de programas de políticas públicas, valendo-se da experiência vivida no Programa de Qualificação em Educação Popular em Saúde do Ministério da Saúde e da Secretaria de Gestão Participativa do mesmo Ministério, o EdPopSUS. Analisa a complexidade do processo de gestão de programas de políticas públicas a nível nacional, o aparato legal que consubstancia esta estratégia administrativa, a importância deste modelo de gestão para a execução das políticas públicas, bem como o acompanhamento através de modelos que contemplam a gestão em rede de atores, proporcionando uma maior participação social, mostrando de forma simples que este modelo privilegia a sociedade, oferecendo resultados que ultrapassam as expectativas, uma vez que o empenho dos atores sociais contribui para um melhor alcance dos objetivos traçados, significando diretamente economia de recursos públicos.
\end{abstract}

Palavras-chave: Administração Pública; Legislação extravagante; Gestão Participativa; Políticas Públicas; Direito Público; Educação Popular em Saúde.

\section{Abstract}

This article examines the legal, social, economic and administrative aspects in the federal public administration strategy, adoption of the Participative Management as management method of public policy programs, drawing on the experience lived in the Qualification Program for Popular Education in Health Ministry of Health and the Secretary of Participatory Management of the same ministry, the EdPopSUS. Analyzes the complexity of the management process of public policy programs at national level, the legal apparatus that embodies this management strategy, the importance of this management model for the implementation of public policies, as well as monitoring through models that consider the management Network actors, providing greater social participation, showing simply that this model focuses on society, providing results that exceed expectations, since the commitment of stakeholders contributes to better achieve the objectives outlined, meaning directly resources economy public.

\footnotetext{
1 Mestre em Administração Pública - ISCTE-IUL. Vice-presidente da Entidade de Serviços Partilhados da Administração Pública-IP da República Portuguesa. Docente titular do Mestrado em Administração Pública e do Mestrado de Sociologia e Planeamento do Instituto Universitário de Lisboa-ISCTE-IUL, Lisboa, Portugal. Docente do CEFA - Fundação Centro de Estudos e Formação Autárquica - Portugal. Docente do INA Instituto Nacional de Administração - Portugal, nos cursos de formação de alta direção da Administração Pública. E-mail: eugenio.antunes@iscte.pt

${ }^{2}$ Mestrando em Administração Pública no Instituto Universitário de Lisboa - ISCTE-IUL. Membro do grupo de Pesquisa "Hermenêutica Jurídica e Análise Transacional" - UERJ/CNPq. E-mail: steniobarretto@gmail.com
} 
Keywords: Public Administration; Extravagant legislation; Participative management; Public policy; Administrative law; Public right; Popular Education in Health. 


\section{INTRODUÇÃO}

Os Agentes Comunitários de Saúde no Brasil vinham sendo privados tanto de programas de capacitação profissionais quanto de acesso e conhecimentos dos usos da rede mundial de computadores, entretanto, desde 2013 puderam abraçar esta possibilidade através da Política Nacional de Educação Popular em Saúde - PNEPS.

A imensidão do território brasileiro, a diferença entre as muitas culturas e regionalidades, a gestão de um elevado número de alunos e a necessidade de centralização do polo de gestão e coordenação em um estado apenas, aparentemente, poderia representar obstáculos para o processo de gestão desta etapa do programa, sendo assim, analisar o desafio e resultados do Programa de Qualificação em Educação Popular em Saúde se torna imprescindível para que futuros estudos possam ser realizados e assim, novas formas de trabalho e gestão possam ser elaboradas para futuros programas, como este que analisaremos.

Com este objetivo, o presente trabalho pretende analisar os meios e métodos de gestão do Programa de Qualificação em Educação Popular em Saúde, mais especificamente do Curso de Qualificação em Educação Popular em Saúde (2013/2015), a forma encontrada pelo Ministério da Saúde para capacitar tais agentes no empoderamento das políticas públicas do SUS, como deseja a PNEPS-SUS, analisando os aspectos jurídicos, sociais, econômicos e administrativos que permeiam a estratégia da Administração Pública federal, buscando na "Teoria do Ator-Rede" uma forma de trazer a participação popular para dentro do ambiente de tomada de decisão e execução de programas de políticas públicas.

Pretende-se ainda analisar, de acordo com estes objetivos da PNEPS/SUS, se os métodos de gestão empregado pela coordenação do programa foram a razão para os possíveis resultados, se foram os mais adequados administrativamente e conforme cada área de apoio ao programa e para entender se estando adequados, estariam também em concordância com a política de Gestão Participativa, com a ação coordenada entre entes públicos e a sociedade, como preceitua a Constituição brasileira. Ainda, pretende-se compreender se o resultado alcançado foi o esperado.

Para conseguir analisar estes aspectos, serão utilizados a revisão bibliográfica, a análise dos relatórios e artigos publicados pela equipe de Avaliação e Pesquisa do Programa e a observação assistemática direta das atividades realizadas durante a realização do curso de qualificação. 


\section{PROGRAMAS DE POLÍTICAS PÚBLICAS NO BRASIL E GESTÃO PARTICIPATIVA}

No início do processo de redemocratização do Brasil, que tem seu marco principal a promulgação da Constituição de 1988, tornou-se imperativo o estabelecimento de uma nova forma de tratamento e contato entre a sociedade e o Poder Público. Esta mesma Constituição, denominada "Cidadã", trouxe em seu texto e no seu espírito o estabelecimento de um Estado Democrático de Direito, onde o Estado deveria aplicar um modelo de gestão pública baseado na participação popular ou social e na descentralização dos poderes e da atividade administrativa do Estado. (Andrade, 2006).

Entretanto, não foi só a Constituição que trouxe para a o campo dos direitos sociais as questões atinentes às práticas de gestão e a política pública, mas foram também os paradigmas jurídicos incorporados após a promulgação desta Constituição, principalmente aqueles derivados de tratados e acordos internacionais, que trouxeram o discurso mais humanitário e da participação da sociedade na gestão pública, como afirmou Telles (1994: 45; 1999).

A condução desta maior participação dos cidadãos nas decisões políticas e sociais visa promover a desburocratização da máquina pública, descentralizar das mãos do governo central a gestão de programas e serviços, partindo por uma mediação de interesses do qual, obrigatoriamente, deve fazer parte a sociedade.

Este modelo de gestão de políticas públicas é o que Andrade (2006) chama de "Teoria do Ator-Rede", uma teoria que apregoa a prática da gestão de políticas públicas com a interação entre diferentes atores, sendo a primeira a ideia a conceituação de "rede", como um fenômeno de gestão como definido por Powell $(1987 ; 1990)$, que define como "arranjos organizacionais híbridos", que "contribuíram para a gestão na sua busca por cooperação, aprendizagem, disseminação de informações, conhecimento, inovação, como formas alternativas à burocracia", que instalada, prejudica o desempenho das organizações públicas. (Andrade, 2006: 54).

A principal vantagem da ideia de "rede" para o processo de gestão é a sua capacidade de comunicação, capaz de produzir uma "produção da organização em vez da organização da produção". (Cooper; Burrell, 1988: 106).

As redes de políticas são apresentadas como "relativamente estáveis e de avanço das relações em que recursos dispersos são mobilizados de modo a orquestrar a ação coletiva em direção a solução de um problema comum. " (Keni, S.; Schneider, 1991: 36). 
No Brasil hoje, a execução das políticas públicas obedece a uma forma de organização administrativa que se assemelha a esta proposta, onde o Poder Executivo estabelece os programas conforme a política pública que deseja implantar, sendo feita a execução pelos Ministérios, e estes, por sua vez, estabelecem a forma com que estas políticas seguirão por uma rede estruturada que conecta estados da federação e consequentemente a "ponta" que se localiza nos municípios, fazendo assim com que as políticas públicas cheguem aos cidadãos.

Entretanto, a "Teoria do Ator-rede" traz um mais um elemento para dentro da rede que se forma entre os entes públicos da administração direta e indireta, ou seja, coloca na mesma rede os atores sociais dos diferentes seguimentos da sociedade para atuarem no campo da discussão, na tomada de decisões e na aplicação prática de tais políticas, bem como a sua futura avaliação e fiscalização, o que visa aproximar ainda mais o cidadão do processo político que o cerca, fomentando o processo que se denomina "Gestão Participativa". Sobre Gestão Participativa define Eduardo Penterich (2006):

Segundo Katz e Kahn (citados por Moggi, 1991), o envolvimento do indivíduo emumsistema, de modo que este considere as metas organizacionais como seus próprios objetivos pessoais, resulta em uma variedade de condutas que apoiam a missão da organização visando obter maior produtividade em suas ações.

A condição básica para ocasionar a internalização dos objetivos do sistema é a auto-realização do indivíduo ao participar na consecução de tais objetivos, pois o indivíduo vê a organização como sua própria criação, participando de suas decisões, de suas recompensas, de modo que a organização se torna parte dele e ele parte dela.

O Instituto ETHOS de Responsabilidade Social define a gestão participativa como a capacidade da empresa de desenvolver técnicas voltadas a compartilhar poder na tomada de decisões, provocar e criar ambientes de motivação, desenvolver sistemas de sugestões eficientes e duradouras, formar e conduzir equipes para a eliminação de problemas (ETHOS, 2003).

Em harmonia com esta definição, é interessante a contribuição de LOPES (2002) no que diz rspeito a participação nos resultados e bonificações: a empresa, além de oferecer participação ou bônus relacionado a desempenho, deve possuir mecanismo que estimule e viabilize a participação dos empregados na sua composição acionária. Criar mecanismos de recompensas para os funcionários que contribuam com a melhoria dos processos internos e eleger representantes de empregados em comitês de gestão estratégica no conselho de administração buscando tornar a relação mais transparente e os vínculos mais sólidos.

Grande parte dos especialistas afirmam não existir fórmulas prontas, cada caso é um caso e o que funciona para uma empresa pode não funcionar para outra. Além disso, é preciso haver vontade política, ou seja, o projeto precisa ser comprado pela alta gerência, e receber o envolvimento de toda organização, o que significa uma mudança cultural profunda. (Penterich, 2006: 108-109). 
O organograma abaixo apresenta o organograma da Secretaria de Políticas de Promoção da Igualdade Racial - SPPIR, uma secretaria de Estado, com status de ministério do Governo brasileiro. Nesta secretaria, cujo nome já carrega o seu escopo, visa à promoção das políticas de igualdade racial. Entre as suas características, encontra-se o estabelecimento de um órgão colegiado, do qual participa a Presidente da República.

\section{SEPPIR - Organograma da Secretaria}

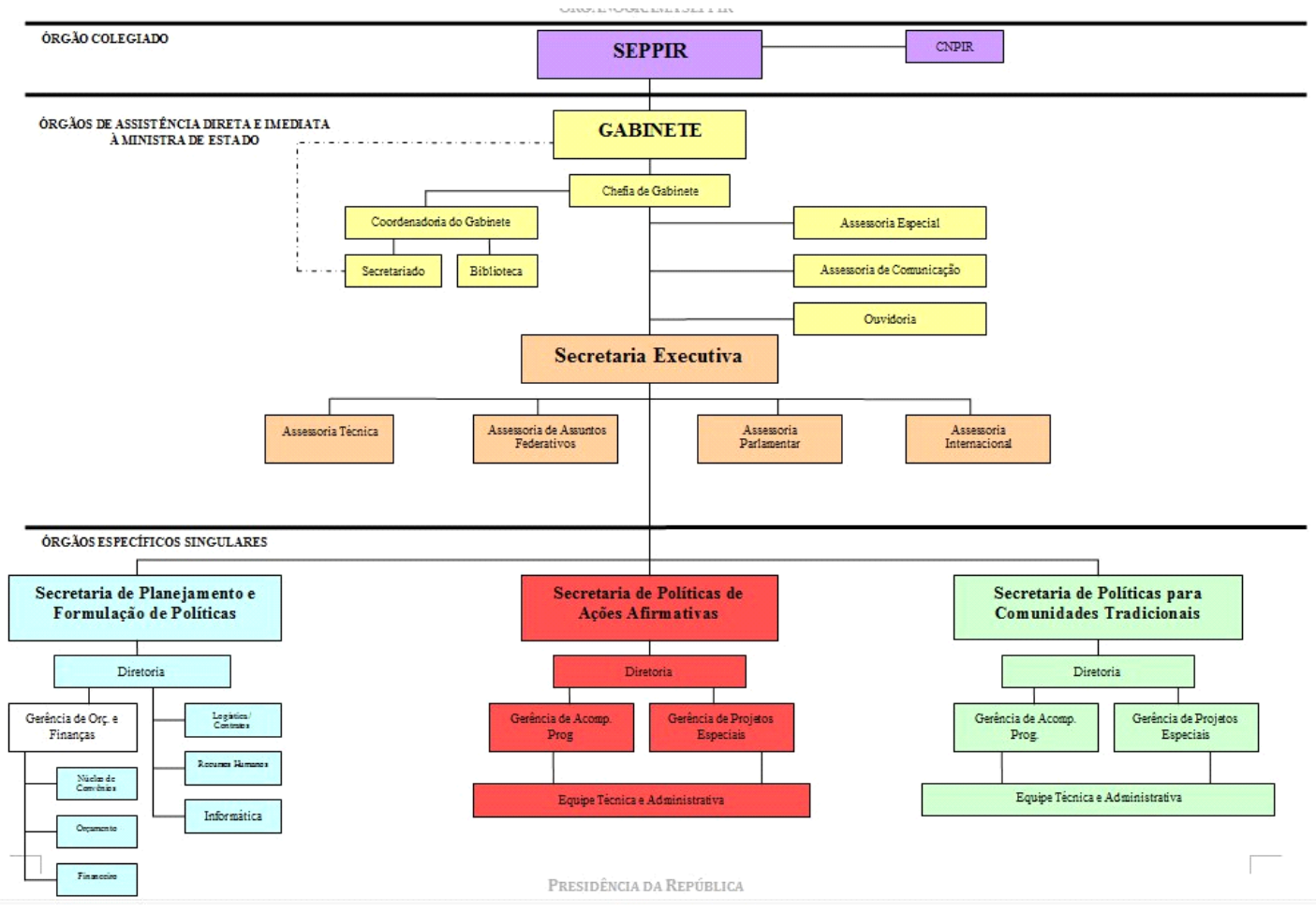

Fonte: SEPPIR

No exemplo da SEPPIR mencionado, esta estabelece as políticas nacionais a serem aplicadas para a área em questão. Seus objetivos são delineados em um órgão colegiado, como se verifica na figura acima, órgão este que transforma as manifestações das muitas organizações sociais existentes dentro desta área e que possuem representatividade nos grupos sociais, discutindo-se com representantes de outras organizações e instituições públicas, incluindo-se universidades e os demais ministérios, bem como representantes dos estados. Forma-se entrão uma "rede intergovernamental" e social, onde as estratégias de ação são uma decisão coletiva, baseada nas propostas de grupo e não somente no escopo estabelecido pelo poder central. Estamos falando de um modelo onde desde a decisão de se estabelecer uma política pública, seu 
orçamento, a forma de gasto e execução passam por decisão colegiada, que envolve todos estes atores mencionados, inclusive os atores sociais. (Andrade, 2006, p.55).

Este modelo de gestão de políticas públicas é a prática de gestão mais comum atualmente na maioria dos programas de políticas públicas e vem sendo estabelecido sistematicamente no país através de uma legislação crescente, incluindo-se a extravagante (Portarias e Decretos) que direciona a prática neste sentido e tem sido objeto d constantes críticas. Este sistema é indicado como um forte instrumento de fomentação da participação social em rede de colaboradores, conectando sociedade e entes governamentais de todas as esferas.

Esta forma de construção coletiva é um meio de intervir na realidade da sociedade, algo que somente ela (sociedade) é capaz de trazer para o gestor. A construção das propostas e o meio que estas propostas serão executadas permite uma "construção coletiva ou solidária". O fato da existência desta construção solidária torna-se justamente o que permite que a organização e execução das políticas se deem de forma a possibilitar a gestão participativa, ou seja, a gestão por tomada de decisão em grupo, integrando as políticas sociais do governo em uma rede una, de forma que se torne possível observar todo o contexto de políticas públicas como uma integração de programas, tornando a vida dos cidadãos dotada de maior qualidade. (Junqueira, 2004, p.133. Apud. Andrade, 2006: 55).

O que se pretende com a Gestão Participativa é que a sociedade contribua com as soluções dos problemas através das propostas que partem de quem os vive.

A rede aqui apresentada necessita de coordenação entre os multiplos atores, estratégias diversificadas para coordenação entre as políticas e gestão dos recursos, bem como pactuação coordenada para a atuação e execução das propostas.

A Gestão Participativa é traduzida em gestão democrática, na qual os atores sociais que compõem esta rede se tornam capazes de compreender a sociedade em que vivem, traduzindo as necessidades desta mesma sociedade em proposta de ação, que por sua vez, se traduzem em políticas públicas que são incampadas pela Administração Pública dentro da sua proposta de trabalho e política de governo, porém deixando de ser um programa que é executado do ápice da pirâmide para baixo, passando a ser um processo onde os atores sociais que representam a sociedade se encontram na posição onde podem influenciar diretamente e discutir com equidade com quem detém o poder, mas que neste modelo o compartilha. $\mathrm{O}$ espaço de poder antes limitado passa a ser compartilhado, trazendo a vida o contexto de democracia e de poder popular (Medina, 2003:29 Apud Andrade, 2006:56). 


\section{MODELO DE GESTÃO PARTICIPATIVA APLICADO EM UM PROGRAMA DE POLÍTICA PÚBLICA: EDPOPSUS}

\section{O Programa de Qualificação em Educação Popular em Saúde - EdPopSUS}

A Educação Popular em Saúde (EPS) é um instrumento de educação continuada que visa promover a aproximação e diálogo entre o saber popular, conhecimento médico científico entre os profissionais e as instituições de saúde. (Bonetti; Pedrosa; Siqueira, 2011).

A EPS é um movimento popular consolidado que busca expressar através das práticas de cuidado em saúde, mas também trabalha na produção de conhecimentos e estes construídos e compartilhados, bem como se envolve ativamente na "constituição de sujeitos e atores políticos" no campo da saúde (Bonetti; Pedrosa; Siqueira, 2011).

Neste sentido, preocupado com o desenvolvimento da participação social na saúde do país, - Ministério da Saúde (MS) estabeleceu e implantou, após longo debate, a Política Nacional de Educação Popular em Saúde para o Sistema Único de Saúde (PNEPS-SUS - Portaria 2.761/2013 do Ministério da Saúde do Brasil), consolidando como "diretrizes pedagógicas o diálogo, a participação e a amorosidade" entre os elementos formadores e para a construção do compromisso com um de democracia e incremento da ação popular, centrado na emancipação dos sujeitos, no caso os profissionais da área da Saúde e aqueles que são atendidos por eles nas comunidades seriam beneficiados.

Em seu texto, a PNEPS-SUS propõe o estabelecimento de uma prática político-pedagógica para canalizar e orientar as ações inclinadas com a "[...] promoção, proteção e recuperação da saúde, a partir do diálogo entre a diversidade de saberes, valorizando os saberes populares, a ancestralidade, o incentivo à produção individual e coletiva de conhecimentos [...]" (Brasil, 2013).

Este é o ponto de partida de um viés político-pedagógico, baseado no sócio construtivismo, entendendo a aprendizagem como um processo de alta complexidade, conectado ao contexto da sociedade atual, e interagindo através da ação com agentes comunitários culturais e locais, com vasta experiência e vivência, mas que estão conectados com a busca por novas experiências, que uma vez confrontadas com outras já experimentadas, favorecem o desenvolvimento de "novos esquemas mentais expressos em conhecimentos individuais e coletivos" (Barilli; Pessôa, 2013).

Neste sentido, Barilli, Barretto, Moura e Menezes (2014), ao descreverem a forma de nascimento da parceria educacional e de gestão para consolidação do programa descrevem: 
Como principal estratégia para contribuir com a consolidação da PNEPS-SUS, foi lançado, em outubro de 2013 o Programa de Qualificação em Educação Popular em Saúde (EdPopSUS - (www6.ensp.fiocruz.br/EdPopSUS ), fruto da parceria entre a Secretaria de Gestão Estratégica e Participativa (SEGEP) do Ministério da Saúde, a Escola Nacional de Saúde Pública (ENSP) e a Escola Politécnica de Saúde Joaquim Venâncio (EPSJV), estas últimas unidades integrantes da Fundação Oswaldo Cruz (Fiocruz), Instituição federal vinculada ao Ministério da Saúde com sede na cidade do Rio de Janeiro e mais 6 centros regionais no território nacional. Criada em 1900, pelo renomado sanitarista Oswaldo Cruz, é a mais importante instituição de ciência e tecnologia em saúde da América Latina, sendo referência em pesquisa, ensino, insumos e cooperação técnica na área da saúde pública. (Barilli et. al, 2014: 2).

A escolha da Escola Nacional de Saúde Pública (ENSP) e o seu Departamento de Educação a Distância (EaD) da Fundação Oswaldo Cruz (FIOCRUZ) além de estratégica, dada a sua localização e experiência no campo da saúde, foi fundamental também em virtude do respeito e respaldo acadêmico que gozam as instituições envolvidas, incluindo-se neste contexto a Escola Politécnica em Saúde Joaquim Venâncio (EPSJV).

A gestão financeira do Programa seguiu os moldes dos demais programas executados pela FIOCRUZ, com a centralização dos recursos em uma de suas fundações internas, que emitia os pagamentos, organizava o recebimento dos recursos e fazia a gestão dos recursos que provinham do Termo de Aditamento assinado entre as instituições e o Ministério da Saúde por via da FIOTEC Fundação para o Desenvolvimento Científico e Tecnológico em Saúde.

A PNEPS-SUS é, portanto, a forma que o Ministério da Saúde encontrou para que os profissionais da Saúde tornassem atores do processo da Gestão Participativa dos programas e políticas públicas do Ministério, trazendo-os para dentro da rede de gestão dos programas, como parte dos atores que compõem o processo de tomada de decisão e de execução das políticas.

\section{O Modelo de Gestão Participativa de Políticas Públicas Utilizado no EdPopSUS}

No que concerne à gestão, o programa foi organizado pela ENSP e EPSJV, em cumprimento à demanda apresentada pela SEGEP-MS, foi necessário o uso de articuladores locais e nacionais para o estabelecimento das propostas de trabalho, para serem executadas por uma Coordenação Nacional do Programa (CNP), que por sua vez, com respaldo da SEGEP-MS e das direções da ENSP e da EPSJV, estabeleceria núcleos de trabalho que pudessem coordenar as atividades de gestão do programa, razão pela qual a CNP se dividiu em Núcleo de Avaliação e Pesquisa (NUAP), Núcleo de Conexões Virtuais (NCV), Núcleo Pedagógico (NP), Núcleo Financeiro (NF) e Núcleo Operacional (NO), todos conectados e alinhados através de reuniões periódicas de avaliação das ações e 
tomadas de decisão, numa gestão participativa, nos moldes da PNEPS-SUS. Deste grupo faziam parte ainda os atores sociais, diretamente ligados às comunidades estabelecidas nos estados onde ocorreriam o curso previsto.

Este processo é o descrito pela literatura como o que permite uma melhoria na organização, sistematizando conhecimentos e experiências (Borghini, 2005), melhora os canais formais e informais de comunicação, promovendo a interdisciplinaridade (Moss; Ritossa, 2007), além da promoção da delegação, empoderamento dos gestores e colaboradores, apoio às medidas criativas, geração de confiança, quebra de rotinas que poderiam prejudicar o desempenho pela geração de apatia e desmotivação e, consequentemente, atuando com perda de criatividade, como lecionam Xu e Rickards (2007).

Assim, os processos decisórios passaram a ser escalonados conforme a competência de cada núcleo de trabalho e de seus integrantes, devendo estes reportarem ao CNP e receberem deste os comandos para execução das atividades. Entretanto, este processo não era "engessado" de forma que impedisse o uso da criatividade pelos gestores dos núcleos mencionados. Pelo contrário, a solução criativa de problemas e conflitos era a linha de trabalho e ação adotada por essas equipes.

Seguindo os preceitos ensinados por Huhtala e Parzefal (2007), foi preciso que a ENSP aceitasse inovar na gestão do sistema, mas a inovação é algo comum para a instituição, porém desta vez o desafio era um pouco diferente, uma vez que tal experiência em Educação Popular em Saúde, para a gestão deste tipo de curso em nove estados da federação não possuía precedentes.

A inovação consistiu em estabelecer o uso do EaD como forma de gestão acadêmica, para centralizar em um só servidor as informações de sala de aula do curso, bem como permitir a extensão do encontro presencial, ampliando a discussão para o ambiente virtual, assim permitiu-se o debate por mais tempo, além de permitir a futura emissão de certificados de participação aos concluintes.

Como o uso da inclusão digital é um importante fator de ampliação da cidadania, tornou-se interessante acrescer na política pública prevista na PNEPS-SUS mais uma política do governo, mesmo que em parte. Como dissertaram Barilli et. al. (2015):

A inserção das Comunidades Virtuais no PNEPS-SUS, portanto, ganha potência na medida em que agrega outros valores à ação política colaborando para incluir os agentes que historicamente convivem com cenários de exclusão, propiciando, por exemplo, o compartilhamento de vivências inter-regionais dentro de um contexto educativo. (Barilli et. al., 2015: 5). 
Assim, encampou-se a ideia de o programa contemplar a inclusão digital pelo EaD. O uso deste meio como inclusão digital também é defendido por Capobianco (2010), como lemos:

Em geral podemos observar três focos distintos no discurso e nas propostas de inclusão. O primeiro trabalha a inclusão digital voltada à ampliação da cidadania, [...] O segundo focaliza o combate à exclusão digital como elemento voltado à inserção de camadas pauperizadas ao mercado de trabalho na era da informação[...]. O terceiro está voltado mais à educação. (Capobianco, 2010: 67, Apud Spillker, 2014: 5).

Assim, como uma solução criativa para se adequar a carga horária do curso e melhorar ainda mais a questão da inclusão digital, os alunos do programa de qualificação teriam que acessar uma plataforma virtual de aprendizagem (AVA) que fora denominada CVA (Comunidade Virtual de Aprendizagem).

Muito criticada foi esta ideia no início, uma vez que a proposta da Educação Popular como instrumento pedagógico é focada no encontro presencial e na participação e partilha da amorosidade humana. Entretanto, os gestores entenderam que a internet tem se demonstrado um ambiente favorável para a partilha desta amorosidade bem como da interação humana. Sendo assim, manteve-se a ideia de levar para além dos quatro encontros presenciais, um tempo de acesso à CVA para o compartilhamento e discussão das experiências vividas durante os encontros presenciais, o que se verificou ser positivo para o avanço da inclusão digital entre os participantes do programa, mas desta vez com foco na educação, pois em uma pesquisa realizada pelo NUAP, que também foi respondida virtualmente através de formulário, constatou-se que $75 \%$ dos participantes do curso que responderam à pesquisa que nunca tinham feito um curso que envolvesse $\mathrm{EaD}$ antes e ao concluírem o curso $96 \%$ dos respondentes disseram que seria possível aprender utilizando-se este método.

A solução criativa funcionou e foi além. Mas esta estranheza com soluções criativas é sempre esperada em grandes organizações e muito mais em gestão de grandes programas de políticas públicas. Segundo Barilli et. al. (2014):

A estranheza de contar com dois Ambientes Virtuais na estrutura pedagógica de um projeto centrado na Educação Popular em Saúde se dissipa a partir do entendimento acerca dos desafios colocados PNEPS-SUS que compreendem a reflexão crítica sobre as práticas educativas junto as comunidades carentes brasileiras por dentro de um processo formativo institucionalmente organizado.

As especificidades decorrentes da formação de um contingente significativo de agentes, de forma descentralizada, dentro de um curto período de tempo, guardando-se os regionalismos de um país continental, certamente impõem pensar meios subsidiem a gestão do processo de ensino para garantir que a aprendizagem se desenvolva a partir e com os sujeitos da 
aprendizagem, sua diversidade cultural e riqueza humana dentro de uma perspectiva da participação e protagonismo social. (Barilli et. al. 2014: 414).

Tal iniciativa permitiu a aplicação de uma solução criativa que fosse capaz de atender a uma demanda que sofreu forte oposição e resistência, uma vez que, como dissemos, uma das premissas da Educação Popular em Saúde é a atividade presencial, o toque, o olhar dos participantes um nos outros e o compartilhamento de experiências. O que fora desenvolvido pela equipe pedagógica e de conexões virtuais foi justamente uma medida criativa que pudesse ultrapassar este problema, como ensinam Cebon, Newton e Noble (1999), ou seja, a adequação da carga horária para a certificação com o uso de um instrumento virtual em um meio onde este era incomum tornou viável um processo que seria complicado e de elevado custo, sem o uso das ferramentas do EaD.

Este modelo de gestão focado em um funcionamento que favorece a gestão por uma procura de novas formas de se fazer as coisas (investigação), deixando de lado um pouco a exploração, ou seja, resolver o que se encontra durante o processo, aparentemente corrobora com a ideia de resultado mais positivo, como referem Vermeulen, Puranam e Gulati (2010) em sua obra.

O modelo focado na solução criativa de conflitos foi o adotado pela equipe de Coordenação Nacional, foi disseminado pelos núcleos do programa, de forma que a solução dos problemas e conflitos, utilizando-se para isso da experiência e do conhecimento de cada membro da equipe, conforme a demanda enfrentada fosse utilizado nas duas fases do tratamento dos conflitos que surgiam no processo de trabalho, permitindo identificar o problema, imaginar a solução mais adequada, analisar os potenciais problemas desta medida escolhida, prever os possíveis erros e danos colaterais, para prevenir e conseguir oferecer uma resposta de reparo adequada. Isto só fora possível como o constante debate proporcionado pelas reuniões periódicas, onde as decisões eram debatidas, tornando-se uma decisão do coletivo, promovendo uma sinergia de ideias e ações em prol do programa. É como relacionam Sousa e Monteiro (2010):

Mediante o recurso a um método de trabalho, coordenado por uma liderança específica, consegue-se potenciar o desenvolvimento da imaginação (na fase divergente), permitindo depois (na fase convergente) escolher as melhores opções entre as geradas em cada etapa do processo. É um método dirigido à promoção da inovação na empresa através da valorização da experiência e do conhecimento dos membros do grupo, numa sinergia dirigida para um objectivo da organização. (Sousa; Monteiro, 2010:41).

Ademais, a equipe de gestão do programa não se limitou a usar apenas as ideias e deliberações da equipe técnica envolvida no trabalho. Seguindo a premissa da Gestão Participativa 
as demandas apresentadas pelos próprios alunos, mediadores e educadores que interagiam e se comunicavam através da plataforma virtual eram interpretadas pela equipe de gestão e transmitidas nas reuniões, estas alimentavam a linha de ação e as tomadas de decisões, fomentando a rede que se discute neste trabalho.

Assim, conclui-se que a metodologia da gestão utilizada pela equipe de gestores da execução do Programa EdPopSUS foi a da Gestão Participativa, estabelecida em critérios onde os atores não possuíam nível hierárquico, mas sim eram ouvidos como colaboradores e com a ideia de participação pela equidade dos atores, bem como estava focada na solução criativa de conflitos e na oitiva das demandas apresentadas pelos envolvidos no grupo, o que possibilitou rápidas respostas aos problemas e conflitos e ao bom resultado do programa, como veremos a seguir.

\section{ANÁLISE DA DOS RESULTADOS DO PROGRAGAMA DE QUALIFICAÇÃO PELO FOCO DA GESTÃO PARTICIPATIVA DO EDPOPSUS}

Observando a análise anterior, cuja observação que se faz é de que a gestão adotada pelo programa possui dois seguimentos. O primeiro é aquele que diz respeito ao modelo de execução e gestão das políticas públicas, neste sentido, a forma que se dá no presente caso é a da Gestão Participativa, ou gestão em rede de atores, um modelo que encampa o Poder Público e a sociedade civil organizada, representada por diversas entidades e o segundo é aquele que diz respeito ao modelo de execução do programa, que tanto usou a Gestão Participativa quando se valeu de ferramentas de gestão, mais aliados aos instrumentos da gestão por investigação (Vermeulen, Puranam e Gulati, 2010), da criativa (Cebon, Newton e Noble, 1999), mas focalizando nos instrumentos de inovação (Huhtala e Parzefal, 2007).

Pode-se assim dizer, que à semelhança de outros modelos, métodos e ferramentas de gestão, inclusive os identificáveis no meio privado, foram usados em conjunto, criando um suporte que permitiu usar a infraestrutura montada para o programa, bem como a infraestrutura das instituições envolvidas, aliando elementos materiais com os recursos humanos disponíveis na diversidade de estados brasileiros envolvidos, com foco no desempenho sem descuidar da qualidade e do ambiente propício ao trabalho em grupo, com notória participação de atores diversificados, método este exigido na própria Política de Gestão Participativa e de Educação Popular para empoderamento político e social.

Sendo assim, a inovação para o uso do EaD em um curso caracteristicamente presencial facilitou a comunicação com os estados participantes, muito distantes entre si, e possibilitou a 
realização de uma capacitação que superou as expectativas tanto do Ministério da Saúde, quanto da própria Fiocruz.

Segundo a previsão do programa, o objetivo principal era ofertar 16.000 vagas e capacitar o mesmo número de agentes comunitários e agentes de vigilância sanitária, entretanto, ao final do Programa foram ofertadas 24.000 vagas. Este aumento de 33,3\% na oferta de vagas só foi possível graças a Gestão Participativa utilizada pelos gestores do Programa, o que gerou empenho dos Núcleos Estaduais na divulgação da proposta, ademais estes colaboraram com parte da gestão da logística para entrega de alimentação e transporte para os alunos e também pela possibilidade de gerir um volume maior de alunos através do ambiente virtual que foi utilizado no processo, como mencionado antes.

Dos 16.000 que se pretendia qualificar, sendo que número ainda não está totalmente consolidado, uma vez que as escolas envolvidas ainda estão certificando os alunos e uma vez que o programa encerrou esta fase final em novembro de 2015, se pode concluir até aquele momento que entre os 24.000 inscritos a taxa de evasão foi de 19,8\% (algo em torno de 4.752 alunos). Considerando estes índices, ainda assim, a meta de qualificação de alunos foi superada, uma vez que cerca de 19.248 alunos foram qualificados, ou seja, 20,299\% a mais que a meta estabelecida pelo Ministério da Saúde.

Segundo a observação assistemática realizada, os principais conflitos e problemas se deram com base nos processos de envio de materiais devido a falhas nos Correios, onde ocorreram alguns extravios de material didático e um caso de extravio de "vales alimentação" para um dos estados, ambos os casos foram resolvidos em tempo, uma vez que havia previsão de que estes problemas pudessem ocorrer.

Em ambos os casos, as soluções foram dialogadas com o coletivo, consultando-se quem possuía maior experiência no grupo de gestores, dialogando em reuniões que eram realizadas inclusive virtualmente para alguns integrantes, dado a distância de alguns em função do programa ter uma abrangência que envolvia múltiplos estados. Esta foi inclusive uma das características da gestão do Programa: o uso de múltiplas plataformas de comunicação entre os gestores, o que permitiu o rápido contato, com reuniões por vídeo conferência, por exemplo. Em programas desta magnitude, é imprescindível uma rápida comunicação e com isso, economizou-se muito em ligações telefônicas e viagens.

Mencionados alguns gastos, a previsão de gastos do empenho de recursos públicos para o programa era de $\mathrm{R} \$ 15.175 .586,86$ (quinze milhões, cento e setenta e cinco mil quinhentos e 
oitenta e seis reais e oitenta e seis centavos). Não é possível constatar ainda se os recursos foram integralmente utilizados, uma vez que o programa ainda não encerrou seu ciclo, estando os gestores no prazo legal para prestação final de contas. Entretanto, pode-se concluir que todas as etapas de execução previstas em contrato, excetuando a etapa final de certificação e a publicação do relatório final, foram realizadas, sendo inclusive possível aferir o número de alunos que concluíram a qualificação, como foi apresentado.

Outrossim, conclui-se que os objetivos previstos foram alcançados e superados, a qualificação dos alunos foi um sucesso, bem como não há registros de problemas maiores que possam influir negativamente nestes resultados esperados, de forma que se pode entender que os métodos de solução de conflitos e solução de problemas com foco na criatividade, o uso da ferramenta da inovação, aliados a Gestão Participativa, possibilitou a execução de um programa de empoderamento de políticas públicas para uma parcela de agentes públicos que trabalham diretamente com o cidadão na atenção básica à saúde pudessem trabalhar melhor os conhecimentos populares e assim desenvolver sua cidadania ainda mais.

Além disso, a gestão participativa, a inovação e a criatividade possibilitaram a economia de recursos públicos e isto se pode afirmar por que a meta de pessoas atingidas na capacitação superou as expectativas dos gestores. Isto significa dizer que foi possível fazer mais com o que se pretendia fazer menos, sendo algo de extrema relevância em se tratando do objetivo do programa, que objetiva tornar os agentes capacitados cientes da importância do seu papel na participação nas políticas públicas de gestão participativa em saúde, através do uso da Educação Popular em Saúde.

Sendo assim, os resultados superados demonstram que a Gestão Participativa é um relevante instrumento de método de gestão de programas de políticas públicas, sendo algo que o governo brasileiro vem implantando e aumentando o uso ao longo dos anos, espera-se bons resultados para o futuro, uma vez que esta Gestão Participativa é o modelo que se entende mais adequado para a participação da sociedade nos rumos das políticas públicas.

\section{CONSIDERAÇÕES FINAIS}

A Gestão Participativa é um importante instrumento de gestão pública atualmente utilizado pelo Governo do Brasil. Este modelo de gestão incorpora a atuação de uma rede de atores, onde estão envolvidos entes públicos e a sociedade civil organizada, com foco da geração de maior participação social nas tomadas de decisão e execução de políticas públicas no país. 
A PNEPS-SUS é uma política que promovida pela SEGEP-MS, que tem por objetivo capacitar trabalhadores do campo da saúde através do uso da Educação Popular em Saúde. Através da PNEPS-SUS, a SEGEP-MS realizou parceria com duas renomadas instituições, vinculadas à FIOCRUZ, para executarem um programa de qualificação, onde se objetivava a qualificação de 16.000 trabalhadores, entretanto este objetivo inicial fora ultrapassado.

Acredita-se que as ferramentas de gestão utilizadas, principalmente a Gestão Participativa propiciou este aumento do número de pessoas capacitadas, uma vez que a participação e a interação de múltiplos atores sociais e instituições envolvidas proporcionaram os elementos necessários para uma melhor divulgação, melhor aproveitamento dos espaços e recursos alocados.

Outrossim, também o uso da mesma Gestão Participativa dentro dos núcleos operacionais de gestão do Programa de Qualificação e do Curso de Qualificação, que se valeu ainda dos métodos da inovação com foco na investigação de métodos de trabalho e gestão, com priorização da criatividade, sem "engessamento" das atividades e funções desempenhadas, focados ainda na realização de uma liderança em forma de participação de todos os atores envolvidos nas tomadas de decisões e na solução dos problemas e conflitos, proporcionou maior empenho e, consequentemente, proporcionou também maior desempenho, que inclusive se refletiu no resultado da qualificação de agentes acima do esperado, no entanto utilizando-se dos mesmos recursos financeiros que tinham sido disponibilizados.

A forma de tratar juridicamente a Gestão Participativa ainda é o uso de diplomas legais extravagantes, principalmente portarias, consubstanciadas na Lei que criou o SUS e no decreto que a regulamenta, mas a mesma vem sofrendo ataques quanto à legitimidade da participação social no contexto em que o atual governo (Dilma Roussef) regulamentou através do Decreto $8.243 / 2014$.

Conclui-se que a Gestão Participativa funciona bem com a gestão de programas de políticas públicas, assim como é muito importante o uso de instrumentos de gestão que permitam um proceder na execução estabelecido pela constante inovação nos processos de gestão e administrativos, a priorização do trabalho criativo que permita aos atores criar e inovar na resposta aos conflitos e problemas gerados.

O não "engessamento" da gestão é o foco que se deve buscar e a resposta para este problema do engessamento pode estar na Gestão Participativa. 


\section{REFERÊNCIAS BIBLIOGRÁFICAS}

AMARAL, Diogo Freitas do, e outros (2006). Curso de Direito Administrativo, 3a ed., Coimbra, Almedina, I.

(2001). Curso de Direito Administrativo, Coimbra, Almedina, II.

ANDRADE, J. C. Vieira. Justiça Administrativa (Lições), 8ª ed., Coimbra, Almedina, 2006.

ANDRADE, Jackeline Amantino de. (2006). Redes de Atores: Uma nova forma de gestão das políticas públicas no Brasil. Gestão \& Regionalidade, №. 64, maio a agosto de 2006. P.52-66. Disponível em: http://www.spell.org.br/documentos/download/21532.

ANDRÉ, Manuel Rodrigues (2006). Menos Estado e Mais Economia. Novo Rumo para Portugal. Dislivro: Lisboa, Oeiras.

BANDEIRA DE MELO, Celso Antônio (2009). Curso de Direito Administrativo. 29 Ed. São Paulo: Malheiros.

BRAVO, M. I. S.; Pereira, P. A. (orgs.) (2008). Política social e democracia. 4a ed. São Paulo (SP): Cortez; Rio de Janeiro (RJ): UERJ.

DIEGUES, G. (2012). A Construção da Participação Social na Gestão das Políticas Públicas: O Protagonismo do Governo Local no Brasil. Administração Pública e Gestão Social, 4(4), 365-380. Disponível em: http://www.apgs.ufv.br/index.php/apgs/article/view/115.

MOREIRA NETO, Diogo de Figueiredo (2014). Curso de Direito Administrativo. 16 edição, Editora Forense, Rio de Janeiro.

MOZZICAFREDDO, Juan (2000a). Estado e Mercado. In Estado-jurisdicional e cidadania em Portugal, Oeiras, Celta Editora.

Estado-Providência e Cidadania em Portugal. 2a Edição, Oeiras, Celta Editora.

CAETANO, Marcello (1980). Manual de Direito Administrativo, I, 10a ed., reimp., Coimbra, Almedina, 1982; II, 9a ed., reimp., Coimbra, Almedina, 1980.

BARILLI E. C. V. C; PESSÔA L. R. A.(2013). Intersetorialidade Saúde e Educação para a Construção de Escolas Promotoras de Saúde: percepções dos Profissionais Ligados ao Curso a Distância Gestão de Projetos de Investimento em Saúde. Tempus Actas de Saúde Coletiva, v. 7, N. n., 2013.

BARILLI, Elomar Castilho; BARRETTO, Stênio de Freitas; LIMA, Carla Moura; MENEZES, Marcos Antônio. (2015). Educação Permanente em Saúde como Pedagogia Voltada à Participação Social: uma experiência em formação de educadores populares. Revista da UIIPS. Instituto Politécnico de Santarém. Unidade de Investigação: Lisbon, Portugal, Vol2., 2014/2015. Disponível em: http://www.ipsantarem.pt/arquivo/5004.

(2014). Avaliação de ambientes virtuais: uma experiência em Educação Popular em Saúde. In: XI Congresso Brasileiro de Ensino Superior a Distância. In: XI Congresso Brasileiro de Ensino Superior a Distância, 2014, Florianópolis. XI Congresso Brasileiro de Ensino Superior a Distância - 
Pesquisa na EaD: reflexões sobre teoria e prática. Rio Grande: UniRede, 2014. v. 1. p. 412-421. Disponível em: http://dx.doi.org/10.13140/RG.2.1.2741.7123.

BRASIL. (2014) Ministério da Saúde. Gabinete do Ministro. Portaria 2.761 de 19 de novembro de 2013. http://bvsms.saude.gov.br/bvs/saudelegis/gm/2013/prt2761_19_11_2013.html.

BOBBIO, Norberto; MATTEUCCI, Nicola; PASQUINO, Gianfranco. Dicionário de Política. 2 v. Brasília: Editora Universidade de Brasília, 2008. p.1, 2010.

BOBBIO, Norberto. O futuro da democracia. Rio de Janeiro: Paz e Terra, 1986. p.43.

BONETTI O.P., PEDROSA J.I.S., SIQUEIRA T.C.A. Educação Popular em Saúde como Política do Sistema Único de Saúde. Rev APS. 2011 out/dez; 14(4), 2011: p. 397-407.

BARBOSA, Pedro Ribeiro. Gestão em saúde: uma abordagem introdutória. P.347-355. Disponível em: http://www5.ensp.fiocruz.br/biblioteca/dados/txt_975731953.pdf. Acesso em: 12 de mar. 2015.

CEBON, P.; Newton, P. e Noble, P. Innovation in firms: towards a framework for indicator development. Melbourne Business School, Working Paper n.ㅇ 99-9, Set. 1999.

GOHN, Maria da Glória. Teorias dos movimentos sociais. Paradigmas clássicos e contemporâneos. São Paulo: Loyola, 1997.

HUHTALA, H. e PARZEFALI, M-R.. A review of employee well-being and innovativeness: an opportunity for a mutual benefit. Creativity and Innovation Management, vol. 16( 3), 2007, p.. 299306.

MACEDO, Joeci Jaques de, Carvalho, Joilson Barroso de; Coutinho, Hellen Rita Menezes de. O Gestor da Saúde no Setor Público. Diretoria de Gestão Pública do Exército Brasileiro. Disponível em: http://dsau.dgp.eb.mil.br/espacoProfissional/farmacia-gestor_saude_setor_publico.pdf. Acesso em: 12 de mar. 2015.

MOSS, S.; RITOSSA, D. (2007). The impact of goal orientation on the association between leadership style and follower performance, creativity and work attitudes. Leadership, vol. 3(4), 2007, p. 433456.

PENTERICH, Eduardo (2006). Gestão Participativa como Parte das Políticas Estratégicas de Recursos Humanos um Estudo de Caso de Uma Multinacional Norte Americana. EGesta, V. 2, N. 1, Jan.Mar./2006, P. 105-124. Disponível em: http://www.unisantos.br/mestrado/gestao/egesta/artigos/57.pdf.

SOUSA, Fernando; MONTEIRO, Ileana. Inovação organizacional: A eficácia do método de resolução criativa de problemas. Rev. Portuguesa e Brasileira de Gestão, Lisboa, v. 9, n. 3, set. 2010. Disponível em: http://www.scielo.mec.pt/scielo.php?script=sci_arttext\&pid=S164544642010000200005\&lng=pt\&nrm=iso. 
TELLES, Vera. (1994). Sociedade civil, direitos e espaços públicos. Revista Pólis. São Paulo, n. 14, p.43-53.

Direitos sociais, afinal do que se trata? Belo Horizonte: Editora UFMG.

XU, F. e RICKARDS, T. Creative management: a predicted development from research into creativity and management. Creativity and Innovation Management, vol. 16, 3, 2007, p. 216-228.

Trabalho enviado em 04 de setembro de 2016.

Aceito em 12 de outubro de 2016. 